\title{
PSYCHE
}

Vox. 57

JUNE, 1950

No. 2

\section{THE INFLUENCE OF TEMPERATURE UPON \\ THE RESPIRATION AND HEART ACTIVITY OF \\ THERMOBIA AND GRYLLOBLATT $A^{1}$}

$\mathrm{By}$

George A. Edwards (Tufts College)

and

Wm. L. Nutring (Harvard University)

A recent survey of the literature concerning the metabolismtemperature response of insects suggested that this large and diverse class makes no metabolic adaptations to fluctuations in environmental temperature. Therefore, it seemed appropriate to investigate several specialized insects to determine if metabolic adaptations are made to particular temperature ranges. The initial experiments included representatives of two primitive orders occupying extremes on the temperature scale. It is hoped that these may serve as limits for future work of similar nature on the insects as a group.

The firebrat, Thermobia domestica Packard (Thysanura), was selected as the representative of a hot environment. The firebrat has a well deserved name in that it is found in hot, damp places such as boiler rooms. It has a temperature preferendum of $32^{\circ}$ to $44^{\circ} \mathrm{C}$, and an optimum of $37.5^{\circ} \mathrm{C}$ and $60 \%$ relative humidity, at which level it completes the life cycle in about three months. It molts and continues to increase in weight throughout the whole life span (Adams, 1933 ; Sweetman, 1938; Woodland, personal communication).

${ }^{1}$ The work described in this paper was done, in part, under contract between the Medical Division, Chemical Corps, U. S. Army and Tufts College. Under the terms of this contract the Chemical Corps neither restricts nor is responsible for the opinions or conclusions of the authors. 
Grylloblatta campodeiformis Walker (Orthoptera) was chosen to represent a cold environment. The grylloblattids generally have been collected in late fall and winter, being found in mountainous areas on hillsides with coarse rock slides, in deep crevices, under stones, or in decaying moss-covered logs and stumps at the margins of glacial bogs. On mild winter days a few have been found crawling on the open snow slopes (Gurney, 1948-extensive bibliography). The nymphal stages are long, in campodeiformis occupying five years, with the eggs laid in the sixth year (Ford, 1926). Its food consists chiefly of softbodied insects.

\section{Material and Methods}

A culture of Thermobia that had been maintained at $37.5^{\circ} \mathrm{C}$ was obtained from Mr. John Woodland, of Harvard University. They were kept in plastic utility dishes in an incubator at $37.5^{\circ} \mathrm{C}$ and $25 \%$ R.H., fed on wheat flour and dried beef, and watered from a vial and wick.

The grylloblattids were obtained from Dr. J. H. Pepper, of Montana State College. They were kept in plastic dishes at $3^{\circ}$ to $5^{\circ} \mathrm{C}$ in a mixture of moss and leaves and fed on pieces of freshly killed flies and roaches.

The oxygen consumption was determined in volumetric microrespirometers (Scholander, 1942), using "Ascarite" to absorb $\mathrm{CO}_{2}$ produced, oxygen from "Oxybombs" to fill the reservoirs, and shell vials of appropriate size for animal chambers. Constant temperature at each level was secured by immersing the respirometers in stirred, plastic, water baths, which were immersed in turn in a large, stirred, thermoregulated water bath. The animals were exposed to each temperature for about $1 / 2$ hours. At the end of each run the animals were weighed and their sex determined.

For determining the heart rate, each insect was coaxed into a short length of glass tubing, the ends of which were then lightly plugged with cotton. This confinement prevented violent struggling and afforded a clear view of a few cardiac chambers. Of the several available grylloblattids, only two adult females proved suitable for accurate observation of heart activity through intersegmental membranes of the anterior abdominal region. Five adult females and four adult males of Thermobia were selected. Each of these specimens was nearly free of scales, while dark material in the crop made 
the heart visible through the mesothorax and first abdominal segment.

The tube containing the insect was placed on a plasticine platform in a porcelain crucible which could be closed with a loosefitting, transparent cover. The temperature of the air in the chamber was taken from a thermometer piercing the cover, (with the bulb close to the specimen). Lower temperatures were obtained by supporting the chamber in a salt and ice water bath. High temperatures were furnished by fitting the chamber into the top of a paraffin oven. For many of the heart rate counts laboratory light was sufficient; for others, a diffuse, water-filtered beam from a microscope lamp was directed into the chamber.

Except at the damaging extremes, Grylloblatta was exposed for an average of 17 minutes to each temperature level. Thermobia was exposed for an average of one hour and ten minutes at each level. At least two readings were made for each temperature, but three or many more were made in most cases. No specimens were used for further recordings, afer being exposed to temperatures that might be considered damaging. In all cases the rates for previously known temperature preferenda were obtained before subjecting a few individuals to lethal limits. During each run it was frequently noticed that struggles or movements of the alimentary tract produced marked irregularities or even brief cessations of heart activity.

\section{RESULTS}

A. Oxygen consumption:

Grylloblatta.-The oxygen consumption of Grylloblatta at various temperature levels throughout the range $-2.5^{\circ}$ to $20.5^{\circ} \mathrm{C}$ is given in Figure 1. The animals remained active for a number of hours at $-5.0^{\circ} \mathrm{C}$ though the oxygen consumption at that temperature was not measurable by the techniques available. The metabolismtemperature curve for Grylloblatta is a straight line (Fig. 1), with an average $Q_{10}$ of 2.7. With increase in temperature there was a regular increase in oxygen consumption up to $20.5^{\circ} \mathrm{C}$. At that temperature the animals became paralyzed quickly so that a full hour exposure was not realized. Subjection of the data to an Arrhenius plot gives a temperature characteristic of 14,600 calories over the range $-2.5^{\circ}$ to $20.5^{\circ} \mathrm{C}$ (Fig. 3).

At $-5.0^{\circ} \mathrm{C}$ the animals were active but movement was noticeably 


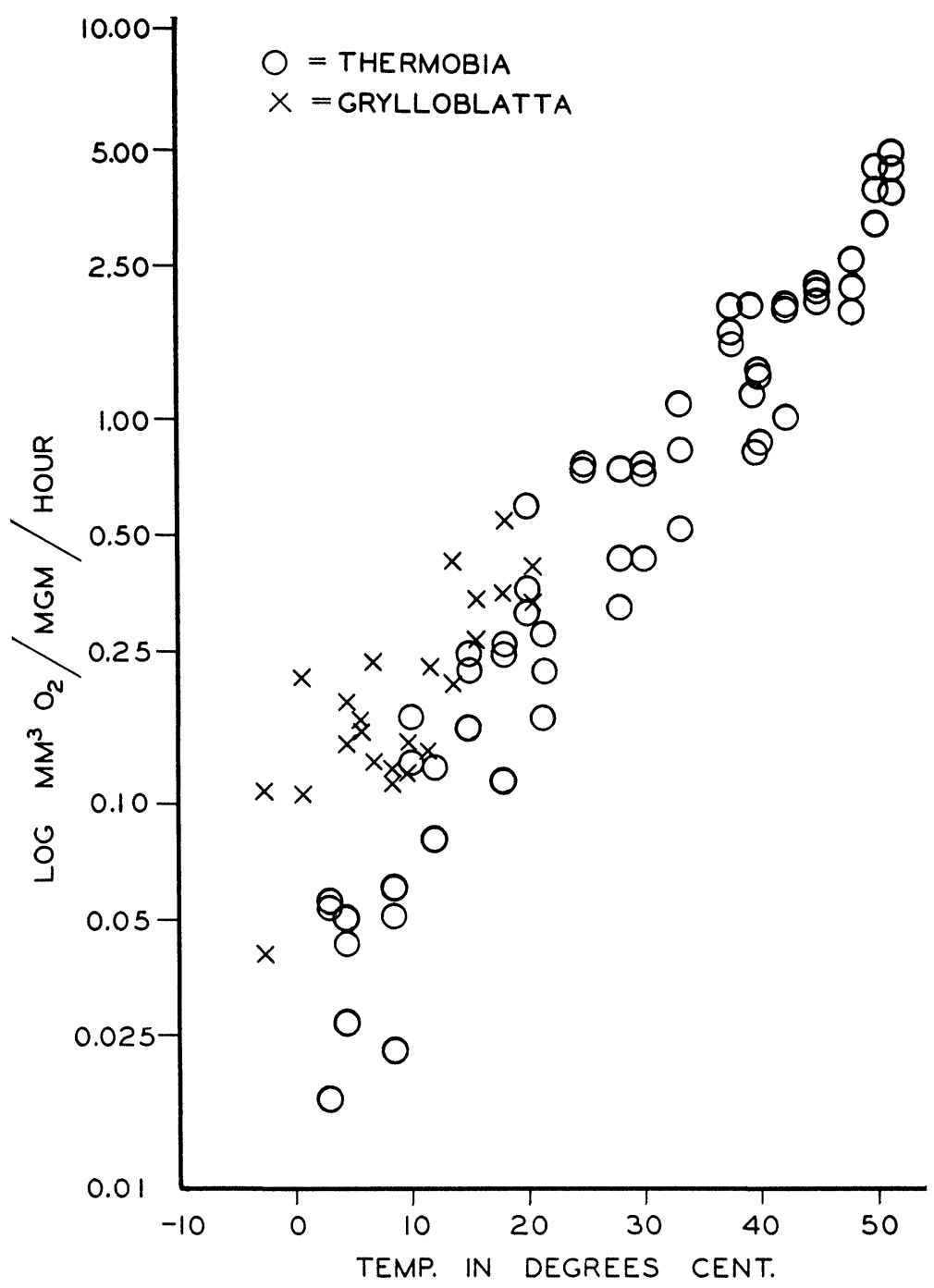

Fig. 1.-Oxygen consumption of Thermobia (circles) and Grylloblatta (crosses) over a range of temperatures. 


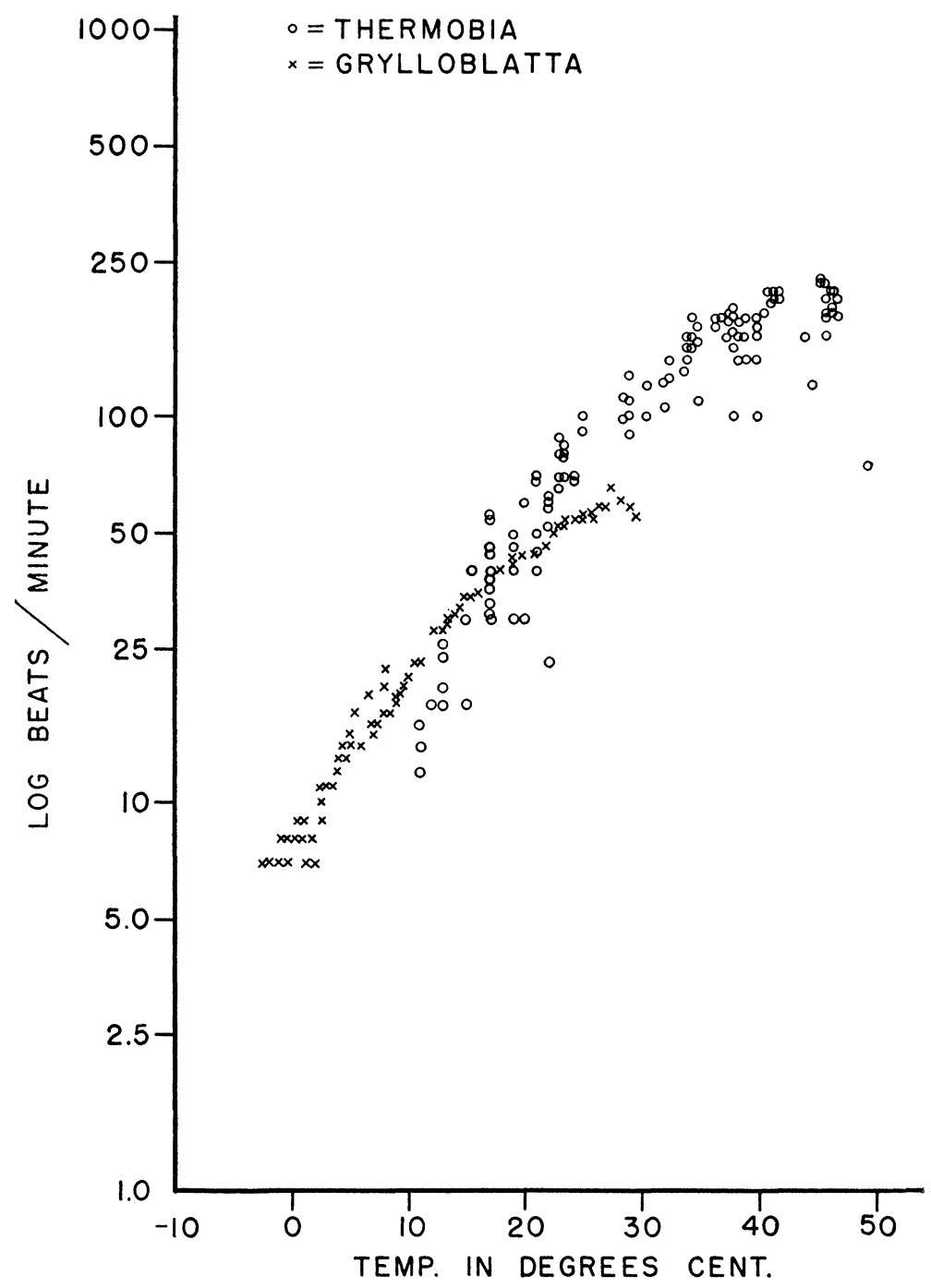

Fig. 2-Heart rate of Thermobia (circles) and Grylloblatta (crosses) over a range of temperatures. 


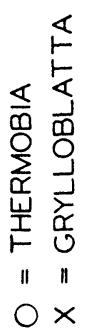

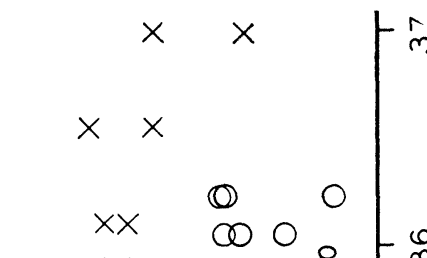

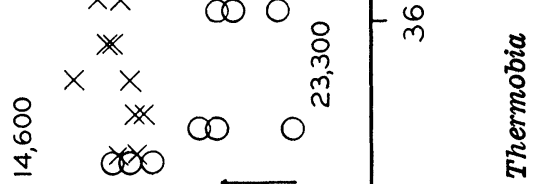

0

000

(D) 0

$\frac{\circ}{\underline{0}}$

(D)

000

(1) 0

(1)

$\infty^{\infty} 0^{\circ}$

$-m$

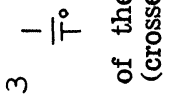

$\stackrel{m}{m}$

造语

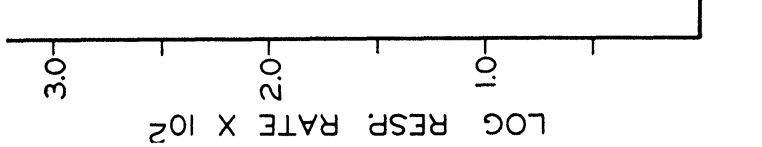




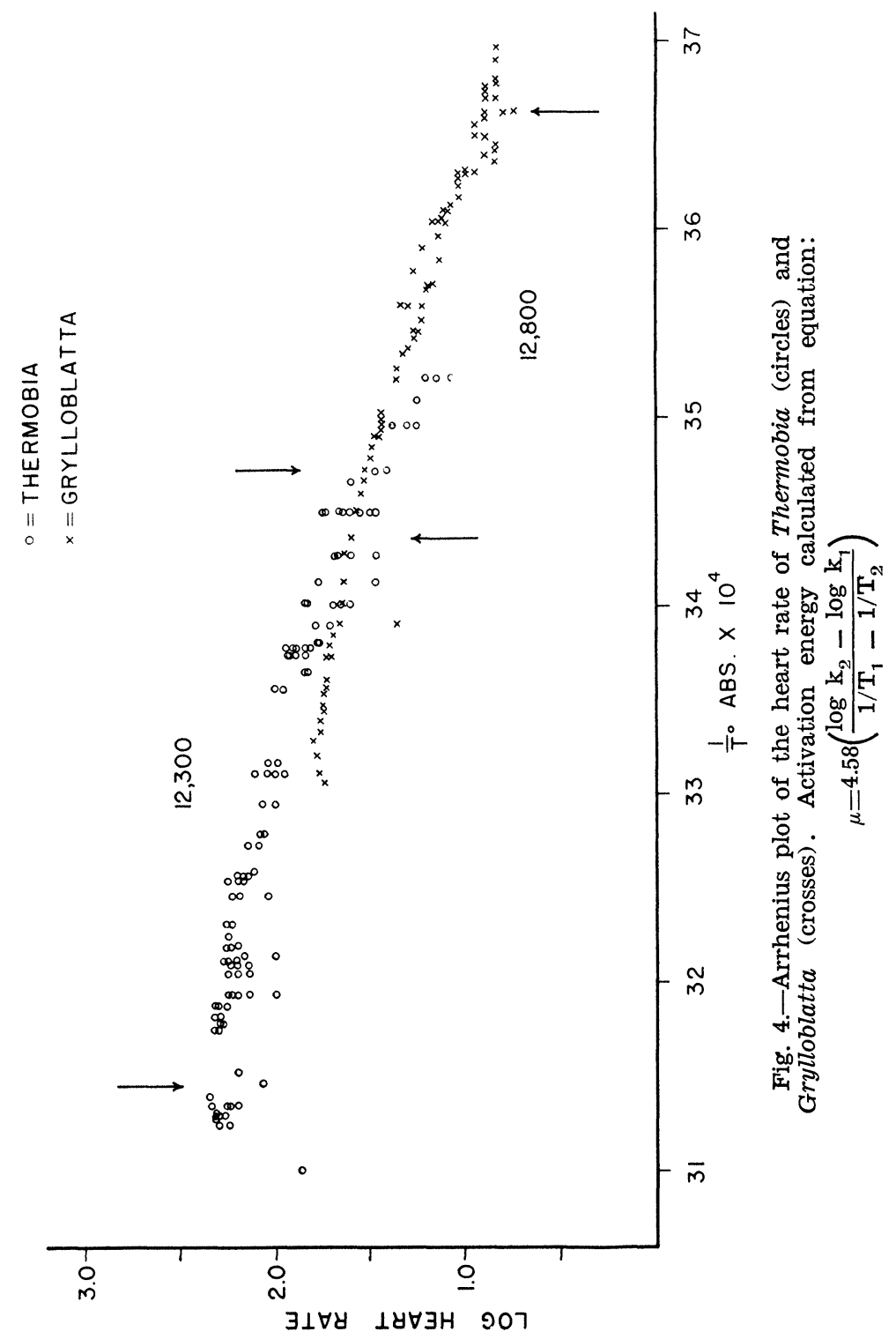


slower than normal. In the respirometers the animals remained quiet in the range $-2.5^{\circ}$ to $11.3^{\circ} \mathrm{C}$. Above this temperature they showed increased activity, struggling violently in the vessels. At $18.0^{\circ} \mathrm{C}$ they struggled for the first half hour and then became abnormally quiet, but still responsive to tapping. At $20.5^{\circ} \mathrm{C}$ the two specimens appeared to be in poor condition, moved feebly, and finally fell to the bottom of the vials and curled up after 20 minutes exposure. At this point the respirometers were shifted to a $6^{\circ} \mathrm{C}$ water bath and the oxygen consumption followed for an hour, during which time it fell continuously. The following day the animals were still paralyzed, showing a low oxygen consumption, feeble heart beat, and increasingly weak reponses to prodding. The female existed two and the male four days in this condition before dying.

Thermobia.-The oxygen consumption of Thermobia was determined at various temperatures in the range $1.0^{\circ}$ to $51.3^{\circ} \mathrm{C}$. The results are given in Figure 1.

The slope of the $\log \mathrm{QO}_{2}$-temperature curve of Thermobia from $12^{\circ}$ to $50^{\circ} \mathrm{C}$ is practically identical with that of Grylloblatta, the average $Q_{10}$ being 2.8. The temperature characteristic for this range was 15,100 calories (see Fig. 3 ). Below $12^{\circ} \mathrm{C}$ the slope increased to 3.8 and the temperature characteristic became 23,300. At $1.0^{\circ}$ and $51.3^{\circ} \mathrm{C}$ the animals were irreversibly injured. Below $12^{\circ} \mathrm{C}$ activity was not observable, though the insects would make slow, appendicular movements when prodded. On return to room temperature, after exposure to the range $3^{\circ}$ to $12^{\circ} \mathrm{C}$, they became normally active within 3 to 20 minutes. Between $12^{\circ}$ and $50^{\circ} \mathrm{C}$ activity appeared normal.

\section{B. Heart activity:}

Grylloblatta.-Over the range $-2.5^{\circ}$ to $29.5^{\circ} \mathrm{C}$, heart rate in beats per minute was recorded and plotted as shown in Figure 2. The heart rate - temperature curve approximates a straight line, although there is a tendency toward levelling off and decline above $20^{\circ} \mathrm{C}$, which may be due to heat damage. The average $Q_{10}$, figured from $-2.0^{\circ}$ to $28.0^{\circ} \mathrm{C}$ is 2.1. Excluding possibilities of damage and resulting deviation at temperature extremes, a mass Arrhenius plot (Figure 4) gives a slope of 2.8 over a conservative intermediate range of $0^{\circ}$ to $18^{\circ} \mathrm{C}$, with a resulting temperature characteristic of 12,800 calories.

At about $2^{\circ} \mathrm{C}$ the beat became rather feeble, at $0^{\circ}$ it was hardly discernible, and after a few minutes at $-3^{\circ} \mathrm{C}$ no form of heart ac- 
tivity was observable. $\mathrm{Up}$ to $20^{\circ} \mathrm{C}$ the heartbeat was strong and regular, but after 15 minutes at $22^{\circ} \mathrm{C}$ diastole appeared incomplete. After 15 minutes at $27^{\circ} \mathrm{C}$ the heart was almost completely relaxed but continued to beat with an increasing amount of fibrillation. This type of activity was maintained for nearly 20 minutes while the temperature was raised to $29.5^{\circ} \mathrm{C}$, at which point all activity ceased.

Thermobia.-The record of heart rate from $11^{\circ}$ to $49.5^{\circ} \mathrm{C}$ is presented in Figure 2. The average $Q_{10}$ calculated from $12^{\circ}$ to $42^{\circ}$ is 2.6. A mass Arrhenius plot (Figure 4), over an intermediate range of $15^{\circ}$ to $45^{\circ} \mathrm{C}$, gives a slope of 2.7 and a temperature characteristic of 12,300 calories.

As the temperature was lowered the heartbeat became more and more feeble, although of ten quite "deliberate", (i.e. with definite pauses between systole and diastole) until, with most specimens, no heart movements were visible after 30 to 60 minutes at $11^{\circ} \mathrm{C}$. At the opposite end of the scale, normal heart activity was observed up to about $42^{\circ} \mathrm{C}$, after which the beat became extremely rapid with incomplete diastole and intermittent fibrillation. Cessation of activity occurred between $45^{\circ}$ and $49.5^{\circ} \mathrm{C}$. General movements of the limbs and body of both Thermobia and Grylloblatta approximated those observed during the respiration experiments.

\section{Discussion}

The results show essential agreement with observations on the activity of Grylloblatta reported by Mills and Pepper (1937). With short exposures, they found that cold prostration set in at $-6.2^{\circ}$, activity was observable from $-5.6^{\circ}$ to about $20^{\circ}$, and paralysis occurred at $24.9^{\circ}$, with $27.8^{\circ} \mathrm{C}$ being fatal. Also substantiated is their statement that Grylloblatta shows no dormancy at low temperatures but probably tries to avoid unpleasant conditions by sunning or seeking shelter.

The results suggest also an answer to the question of what happens to the firebrat when the fire goes out, but do not explain why the animal has a temperature preferendum so high. Data on the firebrat fit the metabolism - temperature curve of other insects for which information is available, suggesting that the wide temperature tolerance of this insect is not due to any special metabolic adaptation.

All insects thus far investigated have the same general metabolismtemperature curve, in all seasons and from all climes. The only 
possible exception is the hive bee, which increases its respiratory rate and activity on either side of a preferred temperature range of $20^{\circ}$ to $25^{\circ} \mathrm{C}$ (Woodworth, 1936). It was expected that Thermobia and Grylloblatta might prove to be exceptions to the rule. However, the slopes of the two oxygen consumption curves are practically identical (2.7 and 2.8); in the intermediate temperatures their respiratory rates overlap; and their $Q_{10}$ 's are in the same range as those of all insects previously reported. They extend the general metabolism - temperature curve, and Thermobia most amazingly so. They are similar to other insects in that they are evidently strictly poikilothermal and utilize only supplementary insulation to offset unfavorable temperatures.

The temperature characteristics obtained over the intermediate temperature ranges agree essentially with previous work on arthropods concerning heart activity and other rhythmic neuro-muscular processes. Comparison of the two sets of data here presented, plus the fact that the heart rate temperature characteristics are not typical of catalyzed oxidative reactions, seem to support the view that respiration is not the fundamental process determining heart rate (see Fries, 1926, for further discussion and bibliography). The temperature characteristics obtained from the oxygen consumption curves are typical values for cellular respiration.

What is now needed most urgently is a thorough study of the biology of Grylloblatta, which would provide a firmer ground for the interpretation of data such as here presented. How does the insect manage to stay within the narrow range of $-5^{\circ}$ to $18^{\circ} \mathrm{C}$ in nature? Does it escape the inevitably severe sub-zero temperatures of its habitat by crawling into deep, rocky, fissures, or in and around roots and in humus where the temperature may remain close to freezing? Is it possible, however unlikely, that the paralysis preceding death at the extremes of its range may be a hibernation state? What relationship exists between the length of the nymphal stages and the low temperature range? What intra- and interspecific variations in temperature responses occur and how do these relate to distribution? A clue to the answer to the last question has perhaps been suggested by Campbell (1948). He reported that a form of Grylloblatta found at Kamloops, under conditions less severe than those of the Canadian Rockies and Montana, did not succumb to warmth as easily as typical campodeiformis usually does. This may represent lack of uniformity in temperature preferenda, but it 
strongly suggests physiological adaptation and perhaps even taxonomic subspeciation.

\section{Summary}

The oxygen consumption, heart rate, and activity at various temperatures over the range $-5.0^{\circ}$ to $51.3^{\circ} \mathrm{C}$ have been determined for the firebrat, Thermobia domestica Packard and for Grylloblatta campodeiformis Walker.

Grylloblatta is normally active from $-2.5^{\circ}$ to $11.3^{\circ} \mathrm{C}$. At lower temperatures activity is decreased and at higher temperatures activity is increased until at $18.0^{\circ}$ the animals become stuporous and at $20.5^{\circ} \mathrm{C}$ become irreversibly damaged by heat. Over the range of temperatures from $-2.5^{\circ}$ to $20.5^{\circ} \mathrm{C}$ the $\log \mathrm{Q}_{10}$ - temperature curve is a straight line, having the slope of 2.7 per 10 degrees. In this range the temperature characteristic for oxygen consumption is 14,600 calories. In the range $-2.5^{\circ}$ to $29.5^{\circ} \mathrm{C}$ the curve relating heart rate to temperature resembles the respiratory curve giving an average $Q_{10}$ of 2.1. In the intermediate range of $0^{\circ}$ to $18^{\circ} \mathrm{C}$ an Arrhenius plot of heart rate gives a slope of 2.8 and temperature characteristic of 12,800 calories.

Thermobia is active throughout the range $12^{\circ}$ to $50^{\circ} \mathrm{C}$. Below $12^{\circ}$ it becomes inactive, and is irreversibly injured by cold at $1^{\circ} \mathrm{C}$. At $50^{\circ}$ activity decreases and heat injury becomes apparent at $51.3^{\circ} \mathrm{C}$. The $\log \mathrm{QO}_{2}$ - temperature curve has a slope of 3.8 per $10^{\circ}$ from $3^{\circ}$ to $12^{\circ} \mathrm{C}$, and a slope of 2.8 between $12^{\circ}$ and $50^{\circ} \mathrm{C}$. Temperature characteristics for respiration in these ranges are 23,300 and 15,100 calories respectively. The heart rate - temperature curve is practically identical with the respiration curve, giving an average $Q_{10}$ of 2.6. The temperature characteristic for heart beat in the intermediate range of $15^{\circ}$ to $45^{\circ} \mathrm{C}$ is 12,300 calories.

These two insects extend the general insect metabolism - temperature curve, and appear to be strictly poikilothermal in that they make no metabolic adaptation to offset unfavorable temperatures.

\section{LITERature Cited}

ADAMS, J.

1933. Biological notes upon the fire-brat, Thermobia domestica (PackCampbell, M. G. ard). Jour. New York Ent. Soc., 41: 557-562.

1948. Notes on Grylloblatta at Kamloops. Proc. Ent. Soc. British Columbia, 45: 1-5. 
FORD, N.

1926. On the behavior of Grylloblatta. Canadian Ent., 58: 66-70.

FrIES, E. F. B.

1927. Temperature and frequency of heart beat in the cockroach. Jour. Gen. Physiol., 10: 227-237.

Gurney, A. B.

1948. The taxonomy and distribution of the Grylloblattidae (Orthptera). Proc. Ent. Soc. Washington, 50: 86-102.

Mills, H. B., and J. H. PePper.

1937. Observations on Grylloblatta campodeiformis Walker. Ann. Ent. Soc. America, 30: 269-275.

SCHOLANDER, P. F.

1942. Volumetric micro-respirometers. Rev. Sci. Insts., 13: 32-33.

Sweetman, H. L.

1938. Physical ecology of the firebrat, Thermobia domestica. Ecol. Monographs, 8: 285-311.

WOODLAND, J.

Personal communication.

WOODWORTH, C. E.

1936. Effect of reduced temperature and pressure on honeybee respiration. Jour. Econ. Ent., 29: 1128-1132.

The C. Andresen Hubbard Collection of Fleas of the Pacific Northwest.- Students of fleas will be interested to learn that the Museum of Comparative Zoology of Harvard University recently received from Dr. C. Andresen Hubbard a collection of carefully prepared and labeled slides representing about 75 species and sub-species of western fleas. The slides are neatly put up in a case, together with a numbered index of the forms represented and a copy of Dr. Hubbard's paper on "The Fleas of California" (1943). Appropriate gaps are left in the case for additional kinds which Dr. Hubbard intends adding from time to time to this set. It now contains paratypes of Megabothris clantoni, Epitedia jordani, and Corypsylla jordani. The Harvard set is Dr. Hubbard's "Depository No. 20," as he is sending similar sets to 19 other institutions here and abroad, in addition to the "Master Collection" to be deposited at the U. S. National Museum. Dr. Hubbard is to be greatly commended for his unusual generosity and foresight in distributing his material so widely so that it may be available to many present and future students of this most fascinating and medically important order of Insects.-J. BequaERT, Museum of Comparative Zoology, Cambridge, Massachusetts. 

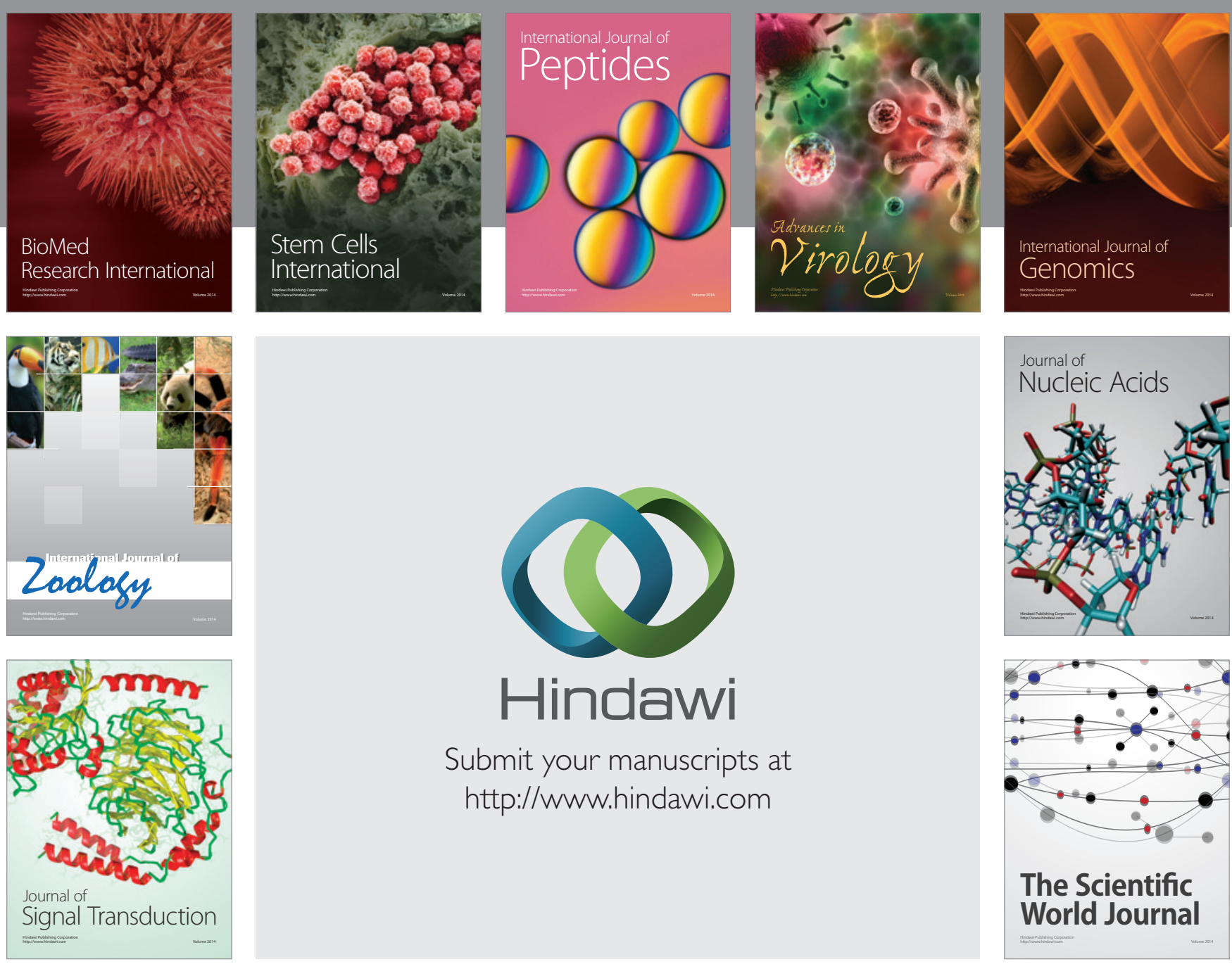

Submit your manuscripts at

http://www.hindawi.com
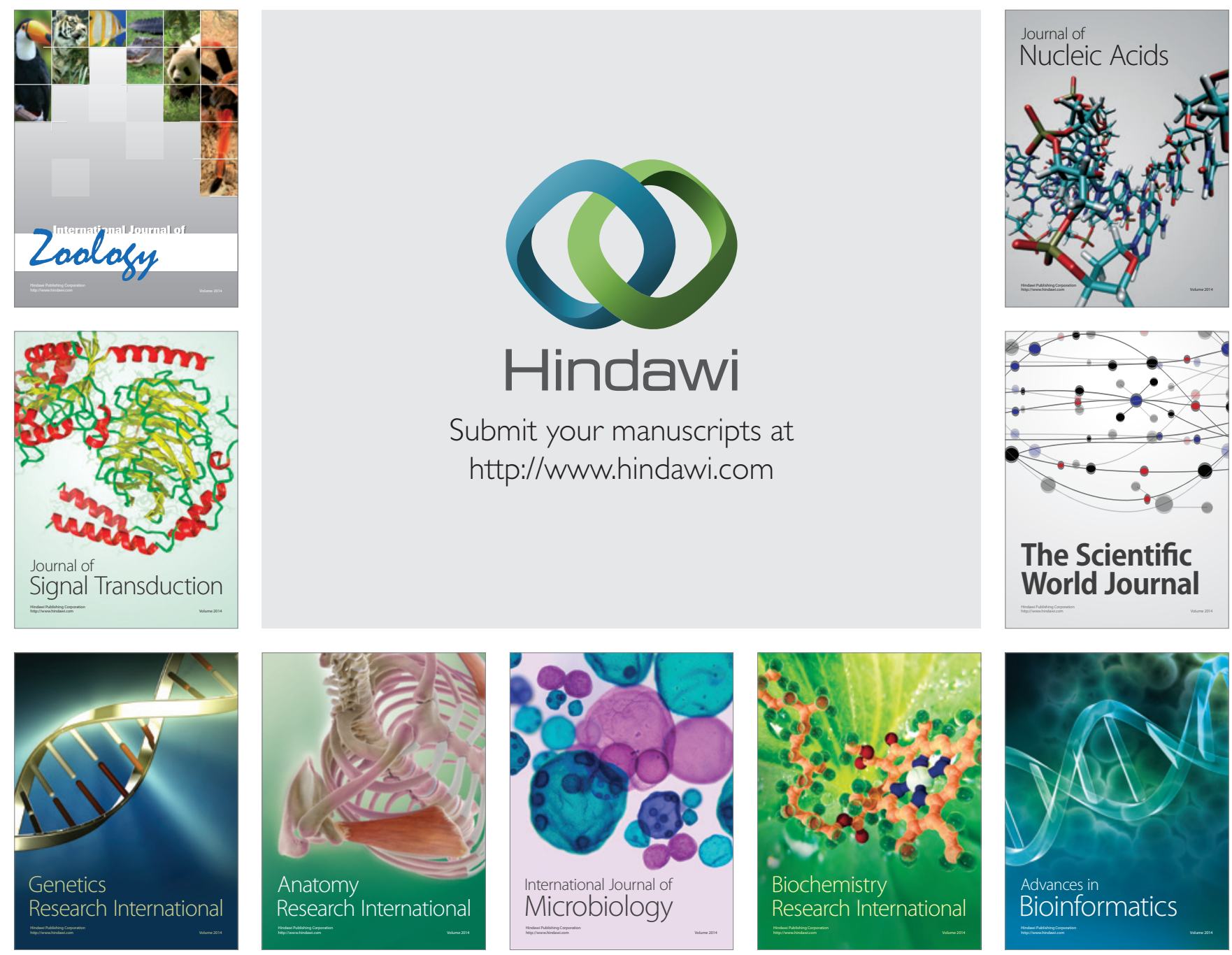

The Scientific World Journal
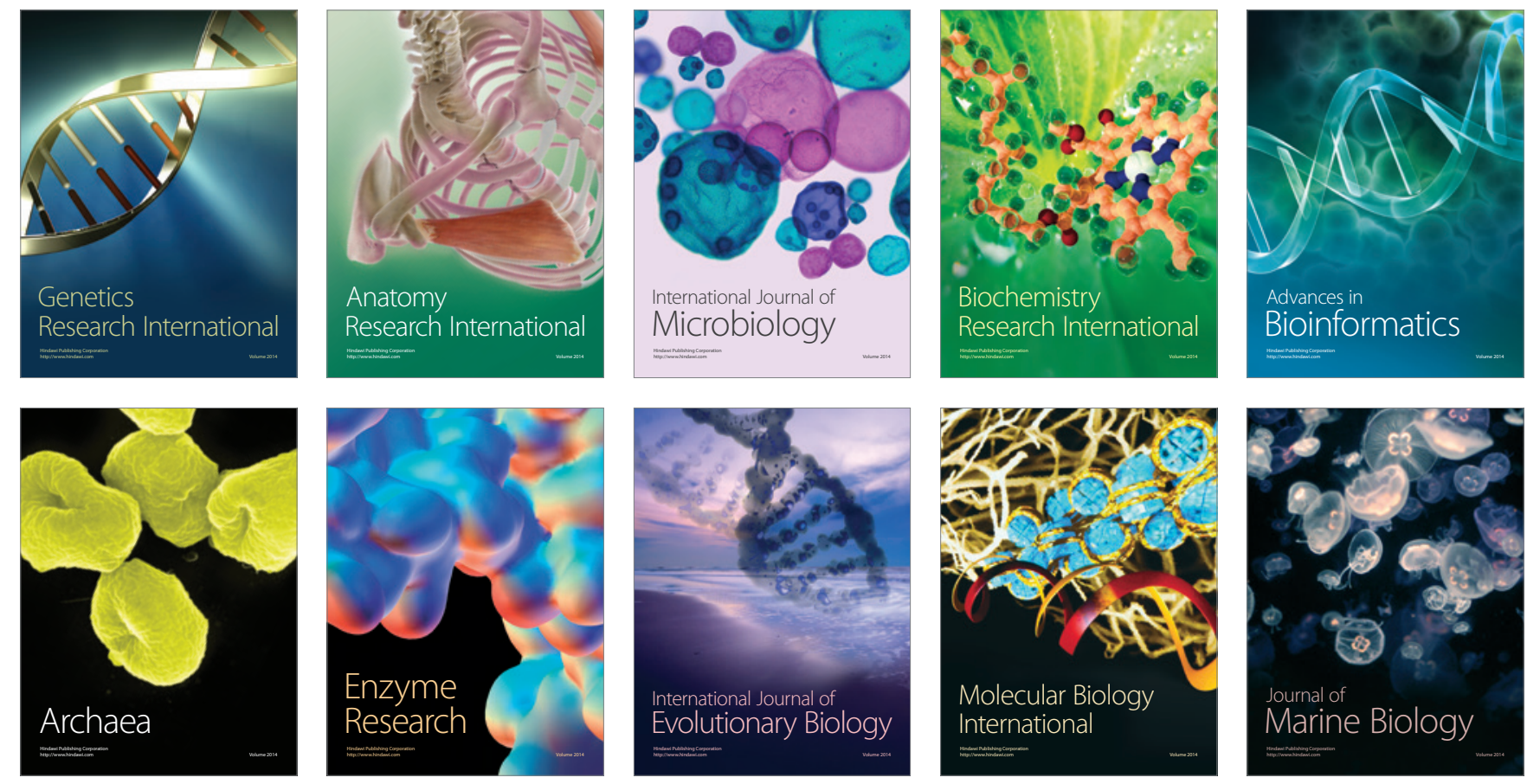